\title{
Ação e reação. Intervenções urbanas e a atuação das instituições no pós-desastre em Blumenau (Brasil)
}

Pedro R. Jacobi. Universidade de São Paulo, São Paulo, Brasil.

Sandra I. Momm-Schult. Universidade Federal do ABC, São Paulo, Brasil.

Noemia Bobn. Universidade Regional de Blumenau, Santa Catarina, Brasil

RESUMO | Em novembro de 2008, no Vale do Itajaí, na Região Sul do Brasil, ocorreu um desastre associado à precipitação extrema de chuvas, que atingiu 1,5 milhões de pessoas, com 135 mortos e cerca de 80.000 desabrigados e desalojados. Após o evento, algumas intervenções foram propostas no Município de Blumenau, tais como, a urbanização da margem do Rio Itajaí-açu, na área central da cidade. $\mathrm{O}$ artigo aborda essa proposta de intervenção, a partir das discussões sobre o planejamento territorial pós-desastre e a atuação das instituições na gestão dos recursos naturais e do espaço urbano. $\mathrm{O}$ caso mostra que, apesar da necessária reflexão sobre o padrão da ocupação urbana, os desastres tornam-se oportunidades para intervenções com caráter de exceção e emergência, sem o devido planejamento e discussão sobre os impactos nos sistemas sociais e ecológicos. A frágil governança deu origem a um conflito entre a Prefeitura Municipal e instituições e atores organizados em torno da proteção ambiental e dos recursos hídricos, o que levou a impasses na intervenção emergencial.

PALAVRAS CHAVE | gestão urbana, gestão ambiental, projeto urbano.

ABSTRACT | In November 2008, in the Itajai Valley in the South Region of Brazil, a disaster occurred with extreme of precipitation affecting 1.5 million people, with 135 dead and around 80,000 displaced or homeless. After the event, interventions were proposed in the City of Blumenau such as the urbanization on the margin of the Itajai-açu river in the central area. The paper addresses this intervention within the context of discussions on post disaster territorial planning and institutional performance in natural resource management and urban space. This case shows that despite the necessary reflection on the pattern of urban occupation, disasters become opportunities for interventions characterized as exceptions and emergency, without an adequate planning and discussion about the impacts of the social and ecological systems. The fragile governance resulted in a conflict between the county administration and the institutions and actors organized around environmental protection and the water resources, which has led to a gridlock in the emergency intervention.

KEY WORDS | environmental management, urban management, urban project.

Recibido el 23 de marzo 2011, aprobado el 27 de febrero de 2012

E-mail: Pedro R. Jacobi, prjacobi@usp.br|Sandra I. Momm Schult, sandra.momm@ufabc.edu.br | Noemia Bohn, noemia@furb.br 


\section{Introdução}

A literatura sobre desastres naturais e, principalmente, sobre enchentes e inundações, está diretamente relacionada com os temas de governança, segurança e vulnerabilidade. Warner (2008) mostra como as enchentes são os desastres mais comuns e devastadores, e como os problemas gerados após um evento expõem a falta de um planejamento do uso e da ocupação do solo, o despreparo das autoridades e a falta de um ethos de prevenção na sociedade. Não se pode também desconsiderar os agravantes associados às desigualdades sociais e à precariedade da estrutura urbana, que se tornam vetores da multiplicação de tragédias recorrentes, causadas pelo descontrole do processo histórico de ocupação urbana.

Esta reflexão está pautada pela noção de risco e segurança como componentes analíticos de uma realidade socioambiental, caracterizada pela fragilidade na capacidade de resposta social, assim como pela falta de ações intersetoriais, em virtude da cultura política institucional pautada pelas ações setoriais, e também por aquelas voltadas para interesses de grupos econômicos e políticos.

Com o objetivo de discutir esses aspectos, apresenta-se o caso de intervenção urbana proposta pós-desastre ocorrido em novembro de 2008, no Município de Blumenau, localizado no Estado de Santa Catarina, na Região Sul do Brasil. Esse evento foi identificado como extremo por não haver registro anterior de precipitação pluviométrica de igual intensidade e pela dimensão dos seus efeitos. $\mathrm{O}$ caso também ilustra e possibilita a análise da governança urbana, considerando o papel de atores e instituições, tais como universidade, comitê de bacia hidrográfica, agências governamentais, organizações de proteção do meio ambiente e Ministério Público, em um contexto de descentralização e participação na gestão dos recursos naturais e do espaço urbano. Discutem-se, assim, as possibilidades de desenvolvimento de uma ação intergovernamental na confrontação dos desastres ante e pós-evento.

\section{Governança do espaço urbano frente aos desastres}

No atual quadro da urbanização mundial, é inquestionável a implementação de políticas públicas orientadas a tornar as cidades social e ambientalmente sustentáveis, como uma forma de se contrapor ao quadro de deterioração das condições da vida urbana, em especial nos países periféricos. Considerando esse quadro, a governança do espaço urbano pode ser a chave no alcance de uma condição de sustentabilidade e redução de vulnerabilidades aos desastres, dentre os quais cumpre destacar, para fins desse artigo, aqueles desastres relacionados aos eventos pluviométricos extremos.

Entende-se, por governança, as reformas administrativas e de Estado que têm como objeto a ação conjunta em busca de uma solução inovadora dos problemas sociais por parte do Estado, empresas e sociedade civil, de forma eficaz, transparente e compartilhada, tendo em vista o desenvolvimento sustentável. Trata-se de uma tendência voltada à autogestão nos campos social, econômico e político, em contraposição à hierarquia e ao mercado, com suas formas de gestão à base de "po- 
der e dinheiro". Ao modelo proposto somam-se a negociação, a comunicação e a confiança (Kissler \& Heidemann, 2006).

Os canais políticos tradicionais têm se mostrado incapazes de atender as demandas sociais, de modo que, a participação popular direta revela-se mais efetiva e mais de acordo com os imperativos de autonomia e descentralização na formulação e implementação das políticas que vêm no bojo da nova governança pública. Os movimentos sociais e organizações não governamentais, centradas na maior parte das vezes sobre reivindicações específicas (proteção ao ambiente, direitos do consumidor, questões de gênero, direitos da criança, etc.), parecem corresponder a uma especialização e uma profissionalização que são características da nova administração pública. Nesse contexto, o espaço público se fragmenta numa pluralidade de campos de discussão e de atuação, cada qual constituído de atores específicos interessados em seus respectivos temas, uma vez que a complexidade crescente dos problemas e das discussões atuais exige que os atores sociais também se especializem (Bento, 2003).

A partir da emergência desses novos sujeitos coletivos de representação política democrática, novos padrões de legitimidade vão sendo forjados. De um lado, do ponto de vista procedimental, faz-se mister a permeabilidade da administração quando da formulação de políticas e normas reguladoras à ampla participação dos setores da sociedade civil interessados e, ao mesmo tempo, o controle por meio de mecanismos mais complexos e sofisticados de responsabilização e prestação de contas (Bento, 2003).

O fato é que a governança surge do enfraquecimento do Estado e da necessidade de envolver outros setores na elaboração e implementação de políticas públicas, como forma de legitimação das decisões tomadas. Grande parte da literatura sobre o tema, considera a nova e/ou boa governança, relacionada ao espaço e aos recursos naturais, como aquela realizada por meio da participação pelo envolvimento e negociação de multi-stakeholders, e pela descentralização (transferindo poder para o governo local - empowerment), considerando a unidade de gestão por bacia hidrográfica e a utilização de mecanismos para a resolução dos conflitos (Solanes \& Jouralev, 2006; Castro, 2007). O uso do termo governança, remete às exigências elementares da democracia, a saber: o acesso à informação, ou seja, ao fato de que os governantes devem favorecer a transparência das decisões, prestando contas aos cidadãos e que, estes últimos, tenham ciência das decisões que lhes atinjam mais diretamente (Scarwell, Kergomard \& Langanier, 2007).

Os estudos da governança da água (Castro, 2007; Castro, 2009) têm focado suas análises nas relações que se desenvolvem em diversos níveis, na dinâmica de organização das bacias hidrográficas (Jacobi, 2004), na lógica nacional e transnacional (Conca, 2006; Ribeiro, 2009; Jacobi \& Sinisgalli, 2009) e na gestão dos serviços (Warner, 2005; Swyngendouw, 2006; Castro \& Heller, 2009). A construção social da água, coloca questões e visões diferenciadas sobre produção, consumo, acesso, mas também sobre tecnologias, capital, mercado, conhecimento e relações sociais. $\mathrm{O}$ uso da água ocorre em diferentes escalas geográficas e sociais e, seu consumo e 
transformação, podem ser objeto de mudanças que não se colocam apenas no plano político-institucional, mas também no organizacional e cultural.

Ao se analisar os desastres envolvendo eventos extremos pluviométricos, há que se partir da premissa de que todo sistema hídrico é parte constitutiva de um sistema ambiental. Atualmente, existe ampla concordância que o uso e as mudanças nos sistemas hídricos não podem ser entendidos, separadamente, de vários temas conexos, como: o planejamento e o uso do solo (Gallart \& Llorens, 2003), mudança climática (Kalnay \& Cai, 2003; Pahl-Wostl, 2002 e 2007; Ojima, 2009), saúde pública, governança da água (Rogers \&Hall, 2004; Solanes \& Jouvralev, 2006; Jacobi, 2009; Jacobi \& Sinisgalli, 2009), gestão ambiental, comércio internacional e segurança ambiental.

Do exposto, pode-se afirmar que a confrontação dos desastres, envolvendo eventos pluviométricos extremos nos espaços urbanos, deve-se dar a partir da abordagem da nova governança pública, que requer ação responsável dos diversos atores, públicos, privados e da sociedade civil, nas diferentes escalas de implementação das políticas públicas de gestão territorial urbana, da água e dos desastres.

\section{Espaço urbano e desastres no Brasil}

Os números de perdas humanas no verão de 2011, especialmente no Estado do Rio de Janeiro, trouxeram à tona o custo social das tragédias relacionadas com os desastres naturais. A forma desordenada do desenvolvimento de cidades e territórios nos últimos 50 anos tem sido a principal causa das tragédias. Os cenários de risco e as fatalidades urbanas, criados pelas ações antrópicas, estão associados à forma de uso e ocupação do solo regular ou informal, e em especial em assentamentos em condição de precariedade. A ocupação em áreas inapropriadas e de grande risco, como encostas e margens de cursos de água sujeitas a alagamentos, enchentes e deslizamentos, é reflexo de uma ocupação inadequada resultante da falta de uma lógica de governança colaborativa.

$\mathrm{Na}$ medida em que o processo de urbanização se intensifica para as áreas mais periféricas, o quadro se agrava. Pela falta de planejamento de uso e ocupação do solo, as ocupações periféricas ocorrem em áreas de risco, aumentando o número de pessoas vulneráveis aos processos naturais (Maricato, Ogura \& Comaru. 2010). A redução da capacidade de escoamento das águas, associada à impermeabilização e precária infraestrutura de drenagem urbana, potencializa transbordamentos, deslizamentos e outros efeitos erosivos.

Em tese, os planos diretores das cidades prevêem instrumentos para enfrentar esses desafios, como a criação de zonas de interesse social e áreas protegidas, transferência do direito de construir, imposto progressivo àqueles imóveis desocupados ou subutilizados, que não cumprem sua função social. Entretanto, a pressão do setor imobiliário provoca desvirtuamentos constantes, e os governos municipais, na sua maioria, cedem aos interesses econômicos, deixando de aplicar as regras existentes e garantindo, assim, a continuidade de um processo que estimula e reforça a ocupação desordenada do solo. Alia-se à incapacidade das políticas urbanas na gestão do uso do solo, a setorialidade na aplicação das políticas ambientais, com 
repercussão no planejamento do território. Instrumentos das políticas ambientais, como o zoneamento ecológico-econômico ou ambiental e o plano de bacia hidrográfica ou de recursos hídricos, não constituem, de fato, macro diretrizes para o ordenamento da ocupação e uso do solo urbano (Steinberger, 2006; Schult, Jacobi \& Grostein, 2009). Os instrumentos citados permitem identificar áreas vulneráveis e estratégias para prevenção, mitigação e adaptação diante de eventos extremos, em unidades tais como áreas costeiras e bacias hidrográficas; porém não são levados em consideração, pelo município no processo de tomada de decisão na gestão do solo urbano. Tal disfunção impacta o ambiente natural urbano, haja vista a simplificação e a inadequação da escala de trabalho adotada, bem como por não observar determinadas exigências metodológicas, tais como: (1) adaptar os usos às potencialidades locais; (2) gerir melhor as obras e os espaços existentes, não apenas sob um ponto de vista técnico (artificialização), mas também sob um ponto de vista organizacional e regulamentar; (3) representar, diagnosticar e avaliar os projetos locais a partir de um sistema mais amplo (bacia hidrográfica), sobre o qual pesa as consequências da tomada de decisão, mas também no qual pode se situar a fonte do problema local e sua solução (Agences de L'eau, 1999).

Pode-se afirmar, com base na leitura dos documentos governamentais, que o principal ente responsável pela resolução desses problemas é o município. Tal afirmação se deve à lógica descentralizadora da Constituição Federal de 1988, cujo pressuposto é que os governos municipais têm maior legitimidade para resolver problemas locais, ou seja, o locus para exercer com maior vigor a cidadania, é a cidade, por conta da maior proximidade entre poder público e sociedade. Porém, as cidades e metrópoles geram problemas coletivos que extrapolam, por sua natureza, a dimensão de um município. Isto demanda mecanismos de articulação contínua entre os entes federativos, incluindo aí a bacia hidrográfica como uma unidade de planejamento e gestão associada aos recursos hídricos.

Também se considera que a comunidade técnica brasileira tem amplo conhecimento sobre a forma de evitar a recorrência destas situações; entretanto, em virtude do que comumente tem se denominado de "falta de vontade política" das administrações municipais e a precariedade da sua estrutura de governança, tal conhecimento técnico não consegue influenciar significativamente na gestão do espaço urbano.

Existe certo consenso, entre os especialistas, que muitas tragédias poderiam ser minimizadas ou mesmo evitadas se o Brasil tivesse um sistema de prevenção de catástrofes minimamente eficiente. Isto demanda a instalação e modernização de equipamentos meteorológicos, como radares e pluviômetros capazes de prever a ocorrência de chuvas intensas com precisão, mecanismos de alerta à população e um mapeamento geológico das áreas de risco. Após os múltiplos desastres ocorridos nos últimos anos, o governo federal decidiu federalizar a questão, chamando para si a responsabilidade de tomar a iniciativa quanto a ações preventivas, e anunciou a criação do Sistema Nacional de Prevenção e Alerta de Desastres Naturais (Ribeiro, 2011).

Entretanto, o que se observa quase sempre é que falta uma ação contínua, uma ação de defesa civil intergovernamental que atue de forma permanente nas regiões 
onde os desastres têm sido recorrentes. Face ao risco de perda de legitimidade do seu capital eleitoral, autoridades desencadeiam operações emergenciais, mobilizando engenheiros, bombeiros, policiais e profissionais técnicos de emergência para atenuar os impactos provocados e reduzir o sentimento de desamparo da população.

O maior desafio da governança do espaço urbano é a integração intergovernamental e o aperfeiçoamento da gestão municipal, que demande gestores qualificados, apoiados por uma administração que desenvolva o planejamento estratégico dos municípios, para que possam ter uma visão de longo prazo e uma gestão baseada mais na prevenção do que na ação emergencial e curativa.

Embora os eventos extremos tenham se ampliado, os problemas gerados pelas intensas chuvas resultam, segundo Ribeiro (2011), de um padrão muito comum de gestão das cidades, onde o planejamento, a regulação e a rotina das ações, são substituídos por um padrão de operações por exceções, com os órgãos da administração pública fragilizados. Na realidade da gestão urbana existente, os previsíveis problemas causados pelos eventos climáticos, somente podem ser respondidos por ações emergenciais. Para Ribeiro (2011), esse fato contribui decisivamente para a reprodução da precariedade das cidades, e perpetua um modelo equivocado de intervençôes sobre o meio ambiente, que potencializa os efeitos de eventos extremos.

As consequências do desrespeito às condicionantes ambientais nas ocupações urbanas são notórias. No nível municipal, é fundamental que o poder legislativo rompa com a lógica clientelista na gestão do espaço urbano. A recorrente discussão sobre a implementação das Áreas de Preservação Permanente (APP), criadas pelo Código Florestal, em áreas urbanas, exemplifica a dificuldade de incorporar, nas legislações municipais, restrições à urbanização que extrapolam o nível de decisão municipal. Da mesma forma, é frequente a alteração de regras mais exigentes no uso do solo, produzidas no âmbito do poder executivo municipal a partir de parâmetros técnicos, quando da aprovação dos Planos Diretores Municipais, em benefício de interesses individuais e de grupos econômicos fortes.

Pode-se afirmar que as cidades brasileiras, atualmente, se defrontam com o desafio da redução dos riscos de desastres, especialmente provenientes de chuvas intensas. Torna-se necessário, portanto, repensar a governança do espaço urbano, tanto na prevenção e alerta de desastres, assim como na sua atuação pós-desastre. Também é necessário, sobretudo, evitar projetos que potencializem a degradação de áreas frágeis e de relevância para o funcionamento dos sistemas naturais. Essa prevenção e ação responsável só poderão ser alcançadas em uma perspectiva de atuação compartilhada e interescalar entre os diferentes setores da sociedade (Berkes, 2002).

A continuidade na omissão, e/ou na insuficiência, e/ou na impropriedade das ações públicas, no tratamento dos gravíssimos problemas associados à ocorrência de eventos extremos, tenderá a ampliar as tragédias em sua intensidade, frequência e letalidade. A confrontação desse problema deve se dar por meio de uma gestão estratégica do ambiente urbano, a partir de uma perspectiva da nova governança pública. 


\section{O desastre de novembro de 2008 no Vale do Itajaí (Brasil) e a atuação das instituições}

O Estado de Santa Catarina, no Sul do Brasil, em especial a Bacia Hidrográfica do Rio Itajaí, possui um histórico de vulnerabilidade associado às enchentes, desde sua colonização no século XIX. O padrão de ocupação, nos fundos de vale próximo aos cursos d'água, potencializa o fenômeno natural e cria uma história de mais de 150 anos de convívio com as inundações. Durante o século XX, em especial a partir dos anos 70, obras estruturais (barragens, canais e diques), assim como instrumentos de informação e gestão (sistema de alerta de cheias, defesa civil, cartas enchentes, pesquisa e estudos), foram implementados a fim de minimizar os impactos dos eventos associados às cheias (Mattedi et al., 2009).

A Bacia Hidrográfica do Rio Itajaí (BHRI) está localizada entre as coordenadas $26^{\circ} 22^{\prime}$ e $27^{\circ} 53^{\prime}$ de latitude Sul e $48^{\circ} 30^{\prime}$ e $50^{\circ} 22^{\prime}$ de longitude Oeste, no Estado de Santa Catarina, Brasil. Esta é a maior bacia da vertente atlântica do Estado de Santa Catarina, e sua paisagem é dividida em três compartimentos naturais: o Alto, o Médio e o Baixo Vale do Itajaí. Possui aproximadamente $15.500 \mathrm{~km}^{2}$ (16,15\% do território catarinense), distribuídos por 50 municípios, de pequeno e médio porte, sendo 49 com sede na bacia. Segundo dados do Censo de 2010 do Instituto Brasileiro de Geografia e Estatística (IBGE), a população destes municípios é de 1.275.014 habitantes, representando 20,40\% da população do Estado de Santa Catarina. Cerca de $70 \%$ do território da bacia encontra-se em municípios com menos de 80 hab/ $\mathrm{km}^{2}$ e/ou menores de 50.000 habitantes. Em contraponto, $40 \%$ da população da bacia reside nos dois centros urbanos, Itajaí e Blumenau. O maior curso d'água da bacia é o rio Itajaí-açu, formado pela junção dos rios Itajaí do Oeste e Itajaí do Sul, no Município de Rio do Sul (Figura 1).

O Município de Blumenau é classificado como centro urbano, a partir da hierarquia do sistema urbano e da caracterização das funções da rede urbana do Vale do Itajaí, que compreende a quase totalidade da Bacia Hidrográfica do Rio Itajaí (Instituto de Pesquisa Econômica Aplicada [IPEA], Instituto Brasileiro de Geografia e Estatística [IBGE] \& Universidade Estadual de Campinas (Unicamp), 2001; IBGE, 2007). Blumenau possui uma população de 309.011 habitantes, a maior da bacia, em um território de $519,8 \mathrm{~km}^{2}$, sendo $206,9 \mathrm{~km}^{2}(39,8 \%)$ de área urbana e $312,9 \mathrm{~km}^{2}$ $(60,2 \%)$ de área rural, apresentando, assim, uma densidade de $594 \mathrm{hab} / \mathrm{km}^{2}$.

Em novembro de 2008, ocorreu em Blumenau, e na região do Médio Vale do Itajaí, uma precipitação intensa durante todo o mês, sendo que nos dias 22 e 23 , o total da precipitação diária foi aproximadamente de $250 \mathrm{~mm}$, intensidade nunca registrada em nenhum dos postos pluviométricos da bacia (Severo, 2009). Tal evento fez com que, à enchente normal, se somasse a enxurrada, provocando deslizamentos e movimentos de massa de grandes proporçóes. O evento em Blumenau afetou diretamente 103 mil pessoas, das quais 5.209 ficaram desabrigadas (perderam suas casas e foram para abrigos), 25 mil foram desalojadas (alojaram-se em casa de vizinhos, parentes ou amigos), 2.383 foram feridas e 24 morreram. Mais de 18 
mil casas, 38 unidades de saúde, 61 unidades de ensino e centenas de quilômetros de rodovias foram danificadas.

FIGURA 1 Localização do Município de Blumenau e da Bacia Hidrográfica do Rio Itajaí (Brasil)

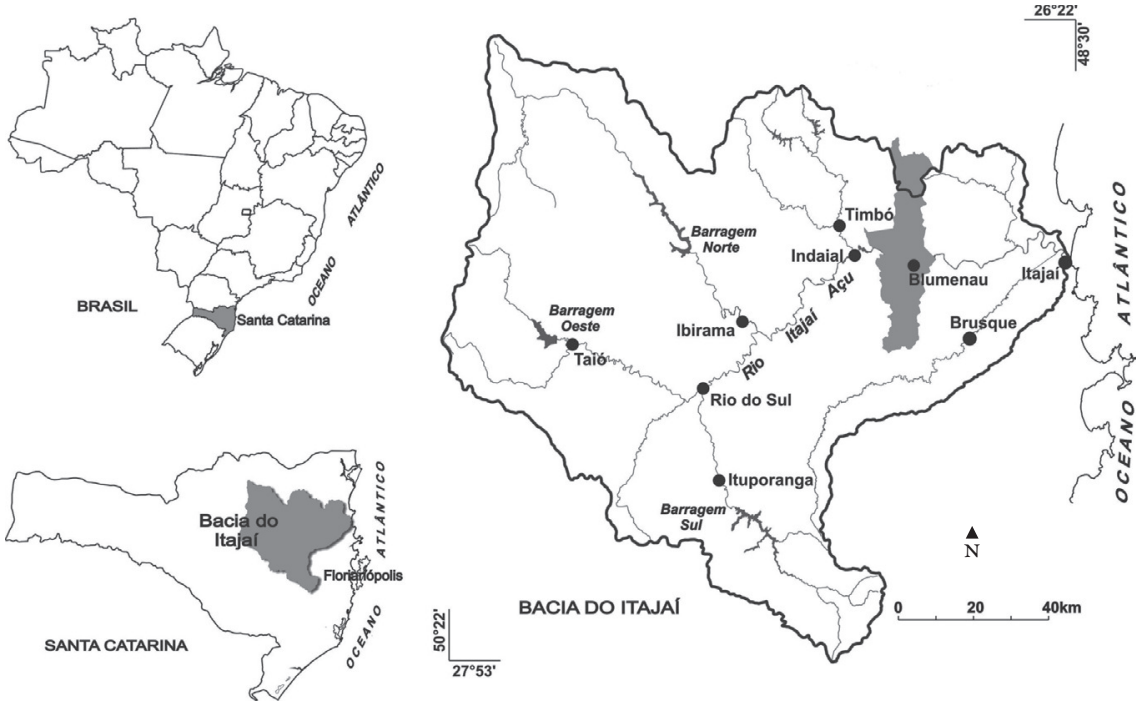

FONTE IPA/FURB.

O evento tomou proporções catastróficas não apenas em Blumenau; em 14 municípios do Estado de Santa Catarina foi decretado estado de calamidade pública e, em outros 63, foi decretada situação de emergência.

Em virtude da situação caótica instalada, o Conselho Estadual de Meio Ambiente do Estado de Santa Catarina (Consema/SC) aprovou a Resolução Consema/SC $\mathrm{n}^{\circ} 18$, de 10/12/2008, autorizando o licenciamento ambiental simplificado, por meio de expedição de Autorização Ambiental - $\mathrm{AuA}^{1}$ para empreendimentos e atividades localizadas em municípios que tivessem declarado o Estado de Calami-

1 De acordo com o artigo $1^{\circ}$ da Resolução Consema nº 18/2008, a Autorização Ambiental deveria atender pelo menos uma das seguintes condições:

I - O licenciamento ambiental se destinar à reconstrução ou à recuperação de empreendimentos ou atividades que foram destruídas, danificadas ou comprometidas pelo desastre que deu causa à declaração do Estado de Calamidade Pública;

II - O licenciamento ambiental se destinar a empreendimentos ou atividades, ainda que inexistentes anteriormente, que visem à prevenção ou à minimização de novos desastres e danos que possam decorrer dos efeitos diretos ou indiretos daquele primeiro que deu causa à declaração do Estado de Calamidade Pública;

III - O licenciamento ambiental se destinar a empreendimentos ou às atividades para socorrer ou assistir as populações afetadas, ou a reabilitar e recuperar os cenários dos desastres.

A resolução mencionada previu ainda em seu artigo $2^{\circ}$, a dispensa dos estudos ambientais, devendo o processo de licenciamento ser instruído exclusivamente com documentos elencados (Projeto do empreendimento, Anotação de Responsabilidades técnica, entre outros). 
dade Pública. A implantação de um estado de exceção na aplicação da legislação ambiental vigente visava, no período de um ano, possibilitar a execução de ações emergenciais frente ao estado de destruição da infraestrutura urbana, tais como vias e pontes, assim como obras de contenção de encostas e deslizamentos. Conforme a resolução citada, foi dispensado o Estudo de Impacto Ambiental (EIA) desses empreendimentos, bem como a realização de consultas e audiências públicas próprias da legislação urbanística e ambiental, assim como a dispensa de aprovação em instâncias deliberativas, como conselhos e comitês. A Resolução Consema/SC n $^{\circ}$ 18/2008, em seu artigo $4^{\circ}$, dispensou também a elaboração prévia de inventário florestal e do levantamento fitossociológico e faunístico, nos casos de autorização de corte de vegetação em até 2,5 hectares, em estágio inicial e médio de regeneração.

\section{Ação do Poder Público no pós-desastre: o projeto de Urbanização da Margem Esquerda do Rio Itajaí-açu}

Em junho de 2008, foi publicada a primeira Revista de Divulgação do Desenvolvimento Urbano de Blumenau, cujo objetivo era apresentar o plano Blumenau 2050, com diretrizes e projetos para o município, em especial para o planejamento territorial, com previsão de total implantação até 2050. O referido plano pretende constituir-se em uma agenda do planejamento territorial e no documento-base de atuação para os próximos governantes do Município de Blumenau (Prefeitura Municipal de Blumenau [PMB], 2008).

A forma e o conteúdo apresentados no plano Blumenau 2050 seguem as características do planejamento estratégico, ao elencar ações pontuais e projetos, a partir de discussão com atores específicos. A crítica sobre a falta de uma visão integrada e socialmente construída, atribuída às diversas experiências do planejamento estratégico no Brasil (Arantes et al., 2002), pode ser aqui aplicada. Os projetos constantes no documento, resultado de discussões com setores convidados pelo poder público, tais como organizações profissionais e empresariais e universidades, foram reproduzidos em maquetes eletrônicas que apresentam uma cidade futura com intervenções de forte apelo imagético, por vezes desconsiderando as características locais.

Dentre as diversas propostas de intervenção urbana previstas no plano, cumpre mencionar, para os fins deste artigo, o Projeto Circuito Ciliar, que prevê intervenções nas margens do rio Itajaí-açu no centro da cidade de Blumenau e na área que corresponde ao antigo centro histórico. O objetivo é criar um circuito de atrativos interligados por esplanadas de caminhada e ciclovias, revitalizando toda área e valorizando a paisagem urbana (PMB, 2008). O projeto mencionado compreende as seguintes intervenções: (1) restauro do Vapor Blumenau; (2) reurbanização da Av. Beira Rio (margem direita); (3) resgate do antigo porto; (4) navegabilidade do rio com a remoção da Pedra da Lontra; (5) locação de atracadores ao longo do rio; (6) urbanização da Margem Esquerda; (7) revitalização do Centro Histórico; (8) revitalização da Rua das Palmeiras. A proposta de intervenção denominada Urbanização da Margem Esquerda, constante do item 6, implica na construção de um 
talude de contenção de concreto, nos moldes da margem direita, que pressupõe a supressão da vegetação original (ver Figura 2).

FIGURA 2 Área central de Blumenau e características das margens do Rio Itajaí-açu

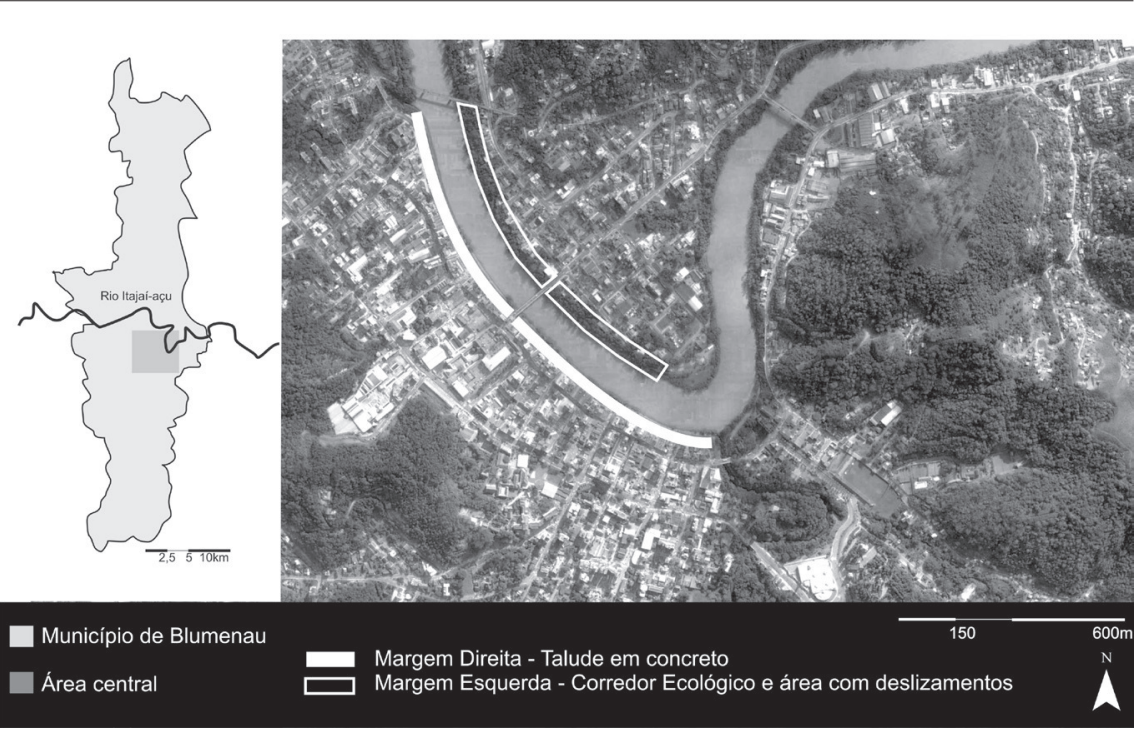

Fonte Google Earth - LeVantamento PMB-2003.

Em 2009, a Prefeitura Municipal de Blumenau (PMB) decide dar andamento às ações de urbanização da margem esquerda, previstas no projeto Blumenau 2050, porém com a justificativa de se tratar de obra de macrodrenagem, importante para a contenção da margem esquerda e, portanto, uma obra prioritária a ser executada no período pós-desastre. Esta decisão não levou em consideração as mudanças ocorridas em função do desastre, tanto do ponto de vista social, com diversas demandas por moradia e infraestrutura destruídas durante o evento, como do ponto de vista do ambiente natural, com inúmeros escorregamentos e alterações na rede hídrica. Um facilitador para o encaminhamento desta proposta, por parte da PMB foi o estado de exceção propiciado pela flexibilização da legislação ambiental, por meio da Resolução Consema/SC no 18/2008, anteriormente citada. Tal resolução possibilitou mudanças significativas, tanto nos processos de aprovação e liberação de recursos, assim como também na disponibilidade de recursos associados ao processo de recuperação urbana e ambiental.

Em 16/7/2009, o Jornal de Santa Catarina anunciou: "Prefeitura retoma Blumenau do futuro". De acordo com a matéria, "Blumenau prepara um pacote de obras de recuperação e ampliação do sistema viário do município". Além de outras fontes de financiamento, o município estaria buscando recursos da ordem de $\mathrm{R} \$$ 63.000.000,00, junto ao Programa de Aceleração do Crescimento (PAC) Drena- 
gem. Dentre as obras incluídas no PAC Drenagem, está a "recuperação da margem esquerda" do rio Itajaí-açu, em um trecho de cerca de um quilômetro. De acordo com o jornal, o trecho receberia ciclovia, pista para caminhada e o talude na margem do rio recuperado.

O projeto executivo de Urbanização da Margem Esquerda, para acesso das verbas do PAC Drenagem, foi elaborado e tramitou junto aos órgãos ambientais, obtendo aprovação com base na Resolução Consema no $18 / 2008$. Como visto anteriormente, tal resolução, por conta do estado de emergência, simplificou o procedimento de licenciamento ambiental excluindo a obrigatoriedade de realização do Estudo Prévio de Impacto Ambiental, de realização da audiência pública, assim como da aprovação do projeto nos conselhos da Cidade e de Meio Ambiente. O projeto previa a supressão total da vegetação e a modificação do perfil natural da margem do Rio Itajaí-açu, na região central da cidade, com a construção de contenção em concreto e reconstituição de taludes com implantação de vias de lazer (pedestres e ciclistas). O objetivo do projeto era assegurar a contenção de deslizamentos pontuais ocorridos na margem e a urbanização da paisagem atual, caracterizada como um corredor ecológico em pleno centro urbano.

\section{Urbanização da Margem Esquerda do Rio Itajaí-açu: a reação ao projeto e os efeitos pós-desastre}

A realização da obra de Urbanização da Margem Esquerda, como uma ação pós-desastre pela PMB, foi sendo conhecida aos poucos por diversos setores da sociedade do município e da região, dada a condição de emergência com a qual o projeto foi elaborado e aprovado. O referido projeto, apesar da dimensão da intervenção na paisagem urbana e natural, não necessitou de trâmites de aprovação em instâncias consultivas e deliberativas. $\mathrm{O}$ caráter conceitual da obra, reproduzindo modelos de intervenção de rigidez de margens, com a utilização de concreto armado e a impermeabilização e supressão de vegetação nativa, surpreendeu diversas entidades e lideranças que viram na obra, um retrocesso em relação às tendências de intervenções em corpos d'água. Apesar do projeto ser proposto em um plano estratégico com vistas ao futuro - Blumenau 2050 -, a forma de elaboração, trâmite e conteúdo se mostraram alinhados com processos de intervenção ambiental e urbana considerados ultrapassados. A aprovação do projeto, nessas condições, somente foi possível pela condição de exceção na legislação ambiental, resultante do estado de emergência pós-desastre.

Diante dos fatos, diversas reações emergiram por parte da sociedade civil. O Núcleo de Estudos Urbanos e Regionais (NEUR), da Universidade Regional de Blumenau (FURB), iniciou uma mobilização entre técnicos para discutir o projeto e propor alternativas. O documento resultante - "Oficina de Propostas Alternativas: Beira Rio Margem Esquerda" - consolidou a discussão do projeto e circulou entre entidades e redes sociais, subsidiando a crítica ao projeto e expondo alternativas à proposta da PMB (NEUR, 2009) ${ }^{2}$. Dentre os aspectos considerados críticos

2 A oficina foi realizada dentro das atividades do programa de extensão da FURB, com apoio do CNPq, nas atividades de pesquisa relacionadas com as áreas de preservação urbanas. 
no projeto, pode-se elencar: a) supressão total da vegetação (aproximadamente 4 hectares); b) alteração da dinâmica do rio, sem considerar o efeito cumulativo de intervenções com essas características na bacia; c) tratar-se de um projeto de intervenção pontual desarticulado de políticas ambientais e urbanas; d) a desfiguração das funções da Área de Preservação Permanente (APP); e) ausência de medidas compensatórias; f) aumento da velocidade da água, com reflexos a montante e a jusante da intervenção; g) engenharia de alto impacto e de custos elevados; h) pressão hidrostática por trás da cortina de concreto e do aterro compactado; i) ausência de discussão pública do projeto; dentre outros.

No documento coordenado pelo NEUR, alternativas ao projeto foram propostas, tais como: a) manutenção da paisagem natural, fauna e biodiversidade; b) utilização de técnicas de menor impacto ambiental; c) manutenção da permeabilidade do solo; d) evitar o estreitamento do canal; e) recuperação e manutenção do talude; f) acesso público ao rio (urbanidade e visual); g) mitigação de prejuízos econômicos, ambientais e sociais (associados às propriedades da paisagem urbana); h) estabelecimento de um novo padrão de intervenção urbana ambiental, cumprindo a função social, ambiental e econômica das APPs.

Paralelamente à ação do NEUR, o Instituto dos Arquitetos do Brasil - IAB - Seção Blumenau, protocolou um pedido de audiência com o Prefeito e com o Secretário de Planejamento Urbano, a fim de discutir o projeto; porém, o mesmo não foi atendido. O curso de Biologia da FURB, em conjunto com a Associação de Catarinense de Preservação da Natureza (Acaprena), organizaram uma manifestação com a participação de estudantes, técnicos e lideranças em frente a PMB, solicitando a revisão do projeto, em especial contra a supressão da vegetação e a mineralização da margem.

Dentre as ações que mais contribuíram para a busca de uma solução de consenso para este problema, foi a instauração de um Inquérito Civil, por parte do Ministério Público Federal, para verificação e acompanhamento da legalidade do referido projeto.

Em virtude da insistência da $\mathrm{PMB}$ em não promover uma discussão mais ampla do projeto com a sociedade civil organizada, o NEUR, a ACAPRENA e o Projeto PIAVA $^{3}$ encaminharam pedido de moção ao Comitê de Gerenciamento da Bacia Hidrográfica do Rio Itajaí (Comitê do Itajaí), que foi aprovado em sua 23a . Assembleia Geral Ordinária, realizada em 3/12/2009. A Moção no 12/2009 do Comitê do Itajaí, enviada às Prefeituras e às Câmaras de Vereadores dos municípios da bacia do Itajaí, às Associações de Municípios do Vale do Itajaí, ao Grupo Técnico-Científico, regulado pelo Decreto no 2.445/2009, aos Ministérios Públicos Estadual e Federal e ao Ministério das Cidades, solicitava à Prefeitura Municipal de Blumenau que apresentasse uma nova versão do projeto, contemplando dentre outros itens, técnicas contemporâneas de intervenção em margens de rios e realização de audiência pública para possibilitar o acesso a informação e a discussão com a comunidade.

3 O Piava é um projeto de recuperação de matas ciliares em pequenos cursos de água e nascentes de iniciativa da Fundação Agência de Água do Vale do Itajaí com financiamento do Programa Petrobrás Ambiental. 
Após o envio da moção ao Ministério das Cidades, houve solicitação expressa desse órgão à PMB, para que enviasse o Projeto de Urbanização da Margem Esquerda para ser apreciado pelo Comitê de Bacia Hidrográfica. Tal exigência teve sua origem em cláusula constante do manual operativo do Edital do PAC Drenagem, que previa a necessidade dos projetos submetidos ao referido edital serem previamente apreciados pelo Comitê de Bacia Hidrográfica, para verificação de sua adequação às diretrizes de gestão definidas no Plano de Recursos Hídricos da Bacia Hidrográfica. Atendendo à solicitação do Ministério das Cidades, a Prefeitura Municipal de Blumenau protocolou, junto ao Comitê do Itajaí, solicitação de análise do projeto "Margem Esquerda do Rio Itajaí-açu", como requisito para aprovação do projeto pelo PAC Drenagem do Ministério das Cidades. A análise do Projeto foi executada pelo Grupo Técnico de Análise de Projeto de Drenagem Urbana (GTAPDU), criado para essa finalidade e vinculado à Câmara Técnica de Planejamento (CT-Plan) do Comitê do Itajaí.

Em 25/2/2010, o Comitê do Itajaí em Assembleia Geral Ordinária aprovou o parecer do GTAPDU, que tinha por objeto a Análise do Projeto de Drenagem Urbana do Município de Blumenau. Nesse parecer, o grupo técnico manifestou-se favorável ao projeto de "Urbanização da Margem Esquerda do Rio Itajaí-açu”, desde que houvesse seu redirecionamento visando à conservação dos aspectos naturais, em detrimento dos aspectos estéticos e urbanísticos.

Posteriormente, o Comitê do Itajaí oficiou à PMB requerendo a reapresentação do projeto, para verificar se foi efetuado o redirecionamento solicitado. Na sequência, coube à CT-Plan a verificação do cumprimento do que havia sido solicitado. Desta análise, foi possível verificar que algumas alterações foram feitas no projeto original, mas estas não redirecionaram o projeto visando à conservação dos aspectos naturais em detrimento dos aspectos estéticos e urbanísticos, como previa a decisão do Comitê do Itajaí. Em virtude deste fato a CT-Plan emitiu o seguinte parecer: "o redirecionamento do Projeto da Margem Esquerda do Rio Itajaí-açu não está integrado às diretrizes do Comitê de Gerenciamento da Bacia Hidrográfica do Rio Itajaí e, portanto, NÃO É FAVORÁVEL à sua execução". Em 16/4/2010, a Diretoria do Comitê do Itajaí aprovou o parecer da CT-Plan e encaminhou ofício à $\mathrm{PMB}$ e demais órgãos públicos interessados no projeto, comunicando sua decisão.

Em 18/6/2010 foi realizada uma reunião, na Procuradoria da República, com integrantes da Caixa Econômica Federal, do Ministério Público Federal, do Ministério das Cidades, do Comitê do Itajaí, da Universidade Regional de Blumenau e da Prefeitura Municipal de Blumenau, para discutir a possibilidade de uma solução de consenso para o Projeto da Margem Esquerda do Rio Itajaí-açu. Como o representante da Prefeitura Municipal de Blumenau não demonstrou interesse em adequar o projeto às diretrizes do Comitê do Itajaí, o representante do Ministério das Cidades comunicou à $\mathrm{PMB}$ que não poderia conceder os recursos pleiteados para o referido projeto diante de tal negativa, dando por encerrada a discussão.

Em setembro de 2011, um novo evento com chuvas intensas ocorreu na Bacia Hidrográfica do Rio Itajaí, afetando a região a montante de Blumenau, especial- 
mente a cidade de Rio do Sul. Em Blumenau, o evento com duração de quatro dias elevou o nível do rio até a cota máxima de 12,80 metros, gerando 668 desalojados e, em Rio do Sul, município mais atingido, o rio atingiu a cota máxima de 12,98, com 3.000 desabrigados.

Após esse evento, novos deslizamentos ocorreram junto à margem esquerda do rio Itajaí-açu no centro de Blumenau, levando grande parte do corredor ecológico existente e pondo em situação de risco cerca de 20 edificações. A situação de emergência novamente criada retomou a necessidade do projeto de contenção e urbanização da margem esquerda, agora questionando o parecer dado pelo Comitê do Itajaí, visto que grande parte do corredor ecológico existente fora levado pelas águas. Assim, criou-se uma pressão política e na mídia sobre o Comitê do Itajaí para a aprovação do projeto de reurbanização da margem esquerda. Em virtude do cenário favorável à implantação do referido projeto, a PMB reapresentou-o ao Comitê do Itajaí, em uma assembleia extraordinária designada especificamente para esta finalidade, e acabou por obter sua aprovação.

Passados quatro anos após o evento, a PMB contraiu um empréstimo junto ao Badesc (Agência de Fomento de SC), visto que a verba do PAC junto ao Ministério das Cidades se encontrava indisponível, iniciando assim as obras. Iniciadas as obras, observa-se que não foram feitas discussões e reflexões que propiciassem alterações no projeto original, tais como as sugeridas inicialmente pelo Comitê do Itajaí, referente à criação de um parque ciliar ou à realização de estudos aprofundados em busca de alternativas que considerassem a complexidade da dinâmica da bacia hidrográfica. Da mesma forma, reiniciaram junto à sociedade civil e na mídia, manifestações contrárias à execução do projeto, em especial a falta de transparência no critério de adoção da solução técnica implantada, dada a amplitude de impactos da obra na paisagem urbana e nos recursos naturais.

O que se percebe neste caso, concreto é que o Comitê do Itajaí, órgão regional responsável pela gestão dos recursos hídricos na Bacia Hidrográfica do Rio Itajaí, deu abertura para a busca de uma solução de consenso; no entanto, a municipalidade rejeitou esta possibilidade. Apoiando-se em Warner, Smits e Winnubst (2009) é possível afirmar que a municipalidade teve dificuldade em perceber que as relações entre os diversos instrumentos de planejamento estão em transformação, criando a necessidade do trabalho intersetorial. Segundo os referidos autores, algumas equipes governamentais de alto escalão ainda consideram isso um fenômeno confuso; contudo, em nível operacional, muitas equipes percebem o sentido de coordenar ações e buscar benefícios conjuntos. A literatura tem demonstrado que é possível caminhar na direção de uma gestão mais integrada dos recursos hídricos com o uso do solo, sem a necessidade de mudar completamente as competências. Correspondências podem ser encontradas dentro das competências de cada ator, apenas melhorando a coordenação e o planejamento conjunto. $\mathrm{O}$ caso em análise coloca em evidência, o esforço do Ministério das Cidades em promover uma governança cooperativa, aliando a política de recursos hídricos com a política urbana; a municipalidade, porém, viu nesta atitude uma interferência em sua autonomia. A sociedade civil organizada, 
representada pelo NEUR, Acaprena, Projeto Piava e IAB, procuraram alertar e impedir a execução do projeto da forma como foi concebido, apresentando alternativas e buscando o diálogo, o que não foi atendido pela equipe do projeto, segura que estava de não ser questionada em virtude do estado de exceção criado após o desastre de novembro de 2008 e, consequentemente, das autorizaçôes obtidas.

Por outro lado, a não realização de uma avaliação de impactos ambientais por conta do estado de exceção, ao contrário de facilitar o processo, criou impasses que culminaram com a protelação da ação em praticamente quatro anos, o que acarretou em diversos prejuízos e desgastes políticos-institucionais. A baixa capacidade de governança urbana ficou evidente na medida em que, a exclusão dos instrumentos de planejamento e gestão, tal como a avaliação de impacto ambiental, não viabilizaram uma solução inovadora que considerasse os diversos agentes e interesses envolvidos na proposta de intervenção.

\section{Discussões e consideraçôes sobre intervenções urbanas e a atuação das instituiçốes no pós-desastre}

A recorrência de desastres de grandes proporções nos últimos anos no Brasil, tem explicitado a problemática associada ao planejamento e à gestão territorial. Na perspectiva da prevenção, as práticas do planejamento urbano se mostram insuficientes para garantir a proteção de áreas e de populações frente à ocupação de espaços ambientalmente frágeis e de risco. Da mesma forma, políticas, planos e projetos vêm sendo implementados sem a devida intersetorialidade e sem a necessária revisão das práticas insustentáveis, predatórias e pontuais sobre sistemas naturais. No campo da gestão, percebe-se a dificuldade do poder público de agir de forma preventiva, mas sim no pós-desastre, com medidas emergenciais próprias de intervençôes estruturais sem a devida avaliação de seus impactos. Entretanto, tem sido positiva a presença de organizações de diferentes setores da sociedade civil, preocupadas em zelar por intervenções e medidas de caráter sustentável.

O caso aqui abordado é representativo desses argumentos. Apesar de tratar-se de uma intervenção urbana pontual, as repercussões do ante e post desastre e suas associações com a governança do espaço urbano, desvelam relações que merecem reflexão, em especial sobre a atuação das instituições na redução aos riscos de desastres.

Um primeiro aspecto a ser discutido é o que Warner (2009) aborda como sendo o estado de exceção na situação do pós-desastre, ou seja, cria-se uma oportunidade para implementação de açôes estruturais, polêmicas e autoritárias que teriam muita resistência, caso não existisse tal estado de emergência. O caso da Urbanização da Margem Esquerda do Rio Itajaí-açu é exemplar. A submissão do projeto ao órgão financiador federal, sem passar por um adequado processo de licenciamento e avaliação ambiental com a realização, entre outros, de audiências públicas, somente foi possível em uma condição de suspensão do princípio da precaução na modificação do meio ambiente urbano. A forma de concepção e implementação da obra, ao invés de prevenir, potencializa a modificação da dinâmica do sistema hídrico e os impactos sobre a biodiversidade, com reflexos diretos sobre o microclima e o ambiente local. 
A suspensão de medidas preventivas e a ação emergencial devem estar amparadas pelo Plano Diretor que, por princípio, direciona as ações, impedindo intervenções pontuais sem respaldo social e político. No caso de Blumenau, contrariando esse argumento, o formato do plano Blumenau 2050, com projetos pontuais e imagéticos, não garante uma agenda de intervenções na construção de um equilíbrio socioambiental, amplamente discutidas e apoiadas por diversos setores da sociedade.

Do ponto de vista do que aqui se denominou reação, ficou evidenciado que a rede de atores e instituições organizadas em torno do meio ambiente e dos recursos hídricos buscou garantir o princípio da prevenção em relação ao Projeto de Urbanização da Margem Esquerda do Rio Itajaí-açu, excluído pelo estado de exceção que se instaurou no Município de Blumenau no período pós-desastre de 2008. Para Berkes (2005), a espaços de cooperação de multi-stakeholders, a classe emergente de instituições para a promoção da "ciência cidadã", e as redes de movimento sociais, entre outros, favorecem o compartilhamento e a co-responsabilização em conexões institucionais na gestão dos recursos naturais. Em especial, Berkes (2005) destaca o papel do Comitê de Bacia Hidrográfica como uma arena privilegiada para esse compartilhamento transescalar e interinstitucional. Porém, no caso analisado, a frágil governança impediu que se construísse uma solução inovadora considerando a diversidade de atores com suas especialidades, competências e capacidades. $\mathrm{Na}$ visão do executivo municipal, a realização de audiências e estudos tratava-se de uma exigência burocrática, e não da viabilização da construção de legitimidade, representação e inovação na gestão urbana.

É importante ainda enfatizar o papel das técnicas, tal como a dos grandes projetos estruturais, que são necessárias em um cenário de prevenção e mitigação de eventos extremos mas que, no caso de excluídas as exigências legais, precisam adotar preceitos de melhor adequação e menor impacto sobre os sistemas sociais e ecológicos.

A avaliação até aqui desse processo, demonstra um avanço nas esferas da sociedade organizada na co-responsabilização pela gestão ambiental e urbana, mas também demonstra a dificuldade, por parte dos governos e em especial o municipal, em lidar com a complexidade que envolve intervenções em um cenário, de um lado de crescente governança, e de outro, de inúmeros desafios da urbanização frente aos desastres naturais. OEURE

\section{Referências bibliográficas}

Agences de L'eau. (1999). La gestion intégrée des rivières: pour une approche globale. v. 1/3. Lyon: Helphi Com.

Arantes, O., Vainer, C. \& Maricato, E. (2002). A cidade do pensamento único. Desmanchando consensos.

$3^{\mathrm{a}}$ ed. Petrópolis: Editora Vozes.

Bento, L. V. (2003). Governança e governabilidade na reforma do Estado: entre eficiência e democratização. Barueri, SP: Manole. 
Berkes, F. (2002). Cross-scale institutional linkages: perspectives from the bottom up. En E. Ostrom, Th. Dietz, N. Dolšak, P. C. Stern, S. Stonich \& E. U. Weber (Eds.), The Drama of the Commons. Washington, D.C.: National Academy Press. pp. 293-321.

Berkes, F. (2005). Conexões institucioanis transescalares. En P. F., Freire, F. Berkes, S. C. Seixas.(Orgs.), Gestão integrada e partidipativa de recursos naturais. Conceitos, Métodos e Experiências. Florianópolis: Associação Brasileira de Pesquisa e Ensino em Ecologia e Desenvolvimento (APED) / Editora Secco.

Conca, K. (2006). Governing Water: Contentions Transnational Politics and Global Institution Building. Cambridge, MA: MIT Press.

Castro, J. E. (2007). Water Governance in the 21st century. Ambiente e Sociedade, 10(2), 97-118.

Castro, J. E. \& Heller, L. (2009). Water and Sanitation Services: Public Policy and Management. Londres: Earthscan.

Castro, J. E. (2009). Systemic Conditions and Public Policy in the water and Sanitation Sector. En J. E. Castro \& L. Heller, Water and Sanitation Services: Public Policy and Management. Londres: Earthscan.

Gallart, F. \& llorens, P. (2003). Catchment management under environmental change: Impact of land cover change on water resources, Water International, 28(3), 334-340.

Instituto Brasileiro de Geografia e Estatística (IBGE). (2008). Regiōes de Influência das Cidades, 2007. Rio de Janeiro: Autor.

Instituto de Pesquisa Econômica Aplicada (IPEA), Instituto Brasileiro de Geografia e Estatística (IBGE) \& Universidade Estadual de Campinas (Unicamp). (2001). Caracterização e tendências da rede urbana do Brasil: configuraçôes atuais e tendências da rede urbana. Brasília: IPEA.

Jacobi, P. R. (2004). A gestão participativa de bacias hidrográficas no Brasil e os desafios do fortalecimento de espaços colegiados. En M. Nobre \& V. Schattan, V. (Orgs.), Participação e Deliberação. Teoria democrática e Experiências Institucionais no Brasil Contemporâneo (pp. 270-289). São Paulo: Editora 34.

Jacobi, P. R. \& Sinisagalli, P. A. (2009). Dimensões Político Instuticionais de Governança na América Latina e na Europa. São Paulo: Annablume.

Jacobi, P. R., Sinisgalli, P. A., Medeiros, Y. \& Romeiro, A. (2009) Governança da Água no Brasil: dinâmica da política nacional e desafios para o futuro. En P. R. Jacobi, P. A. Sinisgalli, $D i-$ mensões Politico Instuticionais de Governança na América Latina e na Europa. São Paulo: Annablume.

Jacobi, P. R., Sinisgalli, P. A. A., Medeiros, I. D. P., Romeiro, A. R. (2009). Governança da água no Brasil: dinâmica da política nacional e desafios para o futuro. En P. R. Jacobi, P. A. de A. Sinisgalli, Y. Medeiros, A. R. Romeiro (Orgs.), Governança da Água na América Latina e Europa (v. 1, pp. 49-82). São Paulo: Annablume.

Kalnay, E. \& Cai, M. (2003). Impact of urbanization and land-use change on climate. Nature, 423, 528-531.

Kissler, L., Heidemann, F. G. (2006). Governança pública: novo modelo regulatório para as relações entre Estado, mercado e sociedade. Revista de Administração Pública, 40(3), 479-99 (maio/jun.), 479-499. http://dx.doi.org/10.1590/S0034-7612200600030000 
Maricato, E., Ogura, A. \& Comaru, F. (2010). Crise urbana, produção do habitat e doença. En P. Saldiva et al., Meio ambiente e saúde: o desafio das metrópoles. São Paulo: Instituto Saúde e Sustentabilidade.

Mattedi, M., Frank, B., Sevegnani, L. \& Bohn, N. (2009). O desastre virou rotina... En B. Frank \& L. Sevegnani, Desastre de 2008 no Vale do Itajai. Água, gente e política. Blumenau: Agência da Água do Vale do Itajaí.

Núcleo de Estudos Urbanos e Regionais (NEUR). (2009). Oficina de Propostas Alternativas: Beira Rio Margem Esquerda. Blumenau: NEUR, Universidade Regional de Blumenau(FURB).

Ojima, R. (2009). Perspectivas para a adaptação frente às mudanças ambientais globais no contexto da urbanização brasileira: cenários para os estudos de população. En D. Hogan \& E. Marandola, População e mudança climática-Dimensões humanas das mudanças ambientais globais. Campinas: Núcleo de Estudos de População (NEPO), Universidade de Campinas/United Nations Fund for Population Activities (UNFPA).

Pahl-Whostl, C. (2002). Towards sustainability in the water sector - The importance of human actors and processes of social learning. Osnabrück (Alemania): Institute of Environmental Systems Research, University of Osnabrück.

Pahl-Wostl, C. (2007). Transitions towards adaptive management of water facing climate and global change. Water Resources Management, 21(1), 49-62. doi 10.1007/s11269-006-9040-4.

Prefeitura Municipal de Blumenau (PMB). (2008). Blumenau 2050. Cidade de Blumenau. Revista de divulgação do Programa de Desenvolvimento Urbano de Blumenau, 1(1). Disponible en http://www.blumenau.sc.gov.br/downloads/seplan/revista_blumenau_2050.pdf

Ribeiro, L. C. Q. (2011). Desastres urbanos: que lição tirar? Disponible en http://web.observatoriodasmetropoles.net/index.php?option=com_content $\&$ view $=$ article $\&$ id $=1555 \% 3$ Adesastr es-urbanos-que-licao-tirar- $\&$ catid $=34 \% 3$ Aartigos $\&$ Itemid $=138 \&$ lang $=p t$

Ribeiro, W. C. (2009). Governança da Água . São Paulo: Annablume.

Rogers, P. \& Hall, A. W. (2004). Effective Water Governance. Global Water Partnership (GWP), TEC background papers n. 7. Suecia: [s.n.].

Schult, S. I. M., Jacobi, P. \& Grostein, M. D. (2010). Desafios de gestão integrada de recursos naturais: entre a gestão de recursos hídricos e a gestão do território na Bacia do Rio Itajaí - Santa Catarina. En W. C. Ribeiro (Org.), Rumo ao pensamento critico socioambiental (v. 1, pp. 241-262). São Paulo: Annablume.

Severo, D. (2009). A metereorologia do desastre. Em B. Frank, L. Sevegnani, Desastre de 2008 no Vale do Itajaí. Água, gente e politica. Blumenau: Agência da Água do Vale do Itajaí.

Steinberger. M. (Org.) (2006). Território, ambiente e políticas públicas ambientais. Brasília: Paralelo 15 e LGE Editora.

Scarwell, H. J., Kergomard, C. \& Langanier, R. (2007). Environnement et gouvernance des territoires: Enjeux, expériences et perspectives en région Nord-Pas de Calais. Lille: Septentrion Presses Universitaires.

Solanes, M. \& Jouralev, A. (2006). Water Governance for Development and Sustainability. Serie Recursos Naturales e Infraestrutura. Santiago: Comisión Económica para América Latina y el Caribe (Cepal).

Swyngedouw, E. (2006). Metabolic urbanization: the making of cyborg cities. En N. Heynen, M. Kaika \& E. Swyngedouw, The Nature of Cities: urban political ecology and the politics of Urban metabolism (pp. 21-40). Londres: Routledge. 
Warner, J. (2005). Multi-Stakeholder Platforms: integrating society in water resource management? En: Ambiente e Sociedade, 8(2), 4-28. São Paulo: Annablume.

Warner, J. (2007). Multi-stakeholder Platforms for Integrated Water Management. Burlington: Ashgate. Warner, J. (2008). The politics of flood insecurity. Wageningen (Países Bajos): University of Wageningen.

Warner, J. (2009). A abordagem de planejamento conjunto para o planejamento hídrico: descobrindo um equilíbrio em três paradigmas de governança. En P. R. Jacobi \& P. de A. Sinisgalli (Orgs.), Dimensões político institucionais da governança da água na América Latina e Europa (v. 2, pp. 103-126). São Paulo: Annablume.

Warner, J., Smits, S. \& Winnubst, M. (2009). Governança local na gestão dos recursos hídricos na Holanda. En P. R. Jacobi \& P. de A. Sinisgalli (Orgs.), Dimensões político institucionais da governança da água na América Latina e Europa (v. 1, pp. 191-225). São Paulo: Annablume. 